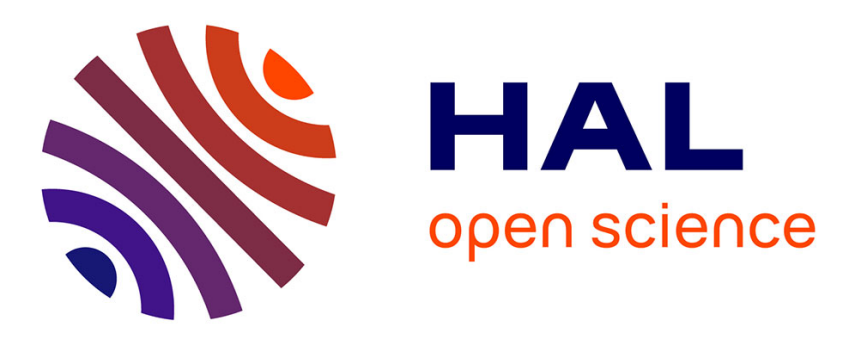

\title{
Sensitivity of the singularity expansion method applied on dipole antenna backscattering
}

François Sarrazin, Ala Sharaiha, Philippe Pouliguen, Janic Chauveau, Patrick Potier

\section{- To cite this version:}

François Sarrazin, Ala Sharaiha, Philippe Pouliguen, Janic Chauveau, Patrick Potier. Sensitivity of the singularity expansion method applied on dipole antenna backscattering. 16th International Symposium on Antenna Technology and Applied Electromagnetics (ANTEM), Jul 2014, Victoria, BC, Canada. pp.1 - 2, 10.1109/ANTEM.2014.6887736 . hal-01435156

\section{HAL Id: hal-01435156 https://hal.science/hal-01435156}

Submitted on 13 Jan 2017

HAL is a multi-disciplinary open access archive for the deposit and dissemination of scientific research documents, whether they are published or not. The documents may come from teaching and research institutions in France or abroad, or from public or private research centers.
L'archive ouverte pluridisciplinaire HAL, est destinée au dépôt et à la diffusion de documents scientifiques de niveau recherche, publiés ou non, émanant des établissements d'enseignement et de recherche français ou étrangers, des laboratoires publics ou privés. 


\section{Sensitivity of the Singularity Expansion Method applied on dipole antenna backscattering}

\author{
François Sarrazin, Ala Sharaiha \\ Institute of Electronics and Telecommunications of Rennes \\ University of Rennes 1 \\ Rennes, France \\ francois.sarrazin@univ-rennes1.fr
}

\author{
Philippe Pouliguen, Janic Chauveau and Patrick Potier \\ Direction Générale de l'Armement \\ France
}

\begin{abstract}
This paper deals with the sensitivity of the singularity expansion method to identify antennas. A dipole antenna is considered and the matrix pencil method is applied on its backscattered field. Then, small variations of length, diameter and load impedance are applied on the dipole antenna and the variation of poles in the complex plane is analyzed. It shows that pole extraction is very sensitive to the dimensions and load impedance of the narrow band dipole antenna.
\end{abstract}

Keywords-singularity expansion method (SEM); matrix pencil method (MPM); resonant pole; antenna identification; sensitivity study

\section{INTRODUCTION}

For many years, the Singularity Expansion Method (SEM) [1], introduced by C.E Baum in 1971, has been widely used for radar applications [2]. The SEM represents a solution of an electromagnetic problem in terms of poles. These poles being independent of the direction of the incoming wave and the polarization, it makes the SEM very relevant for target identification. The SEM has also been applied in antenna domain to model the antenna effective length with only a few sets of parameters in order to reduce the amount of data needed to characterize the antenna [3-4]. More recently, the SEM has been used in a physical way to identify antennas [5]. Indeed, it is shown in [5] that resonant poles correspond to the natural resonances of antennas, especially for narrow band ones. Moreover, we know that poles can be extracted from antenna backscattered field and these poles are similar to those extracted from the radiated field [6]. The objective of this paper is to look at the sensitivity of the SEM regarding the antenna considered in order to be able to discriminate two antennas with close dimensions. Therefore, we consider a dipole antenna and poles are extracted for several dipole antenna lengths, diameters and also load impedances.

\section{SEM THEORY}

The SEM allows modeling the late time response of an antenna as a decay exponential sum with only a few sets of parameters as

$$
y(t) \approx \sum_{n=1}^{N} R_{n} e^{s_{n} t},
$$

where $y(t)$ is the antenna response, $s_{n}$ is the $\mathrm{n}^{\text {th }}$ pole, $R_{n}$ is the residue associated to the $\mathrm{n}^{\text {th }}$ pole and $N$ is the number of poles. Each pole is defined as $s_{n}=\alpha_{n} \pm j 2 \pi f_{n}$ where $\alpha_{n}$ is the negative damping coefficient of the $\mathrm{n}^{\text {th }}$ pole and $f_{n}$ is the resonant frequency of the $\mathrm{n}^{\text {th }}$ pole. There are different numerical methods to extract poles from antenna backscattered field. In this paper, we use the Matrix Pencil Method using a total least square approach [7].

\section{SENSITIVITY STUDIES}

\section{A. Length variation}

In this part, the sensitivity of the SEM as a function of the length $\mathrm{L}$ of a dipole antenna is studied. We consider a thin dipole antenna with a fixed $\mathrm{L} / \mathrm{D}$ ratio of 700 , where $\mathrm{D}$ is the diameter. It means that $\mathrm{D}$ is set up with respect to L. Its load impedance is $75 \Omega$. Poles extracted from the dipole antenna backscattering in the boresight direction are presented in the complex plane in Fig 1 for $\mathrm{L}=20 \mathrm{~mm}$ to $\mathrm{L}=50 \mathrm{~mm}$ with a 2 $\mathrm{mm}$ step. Since resonant poles are complex conjugates, only the poles with positive resonant frequencies are shown in all the figures.

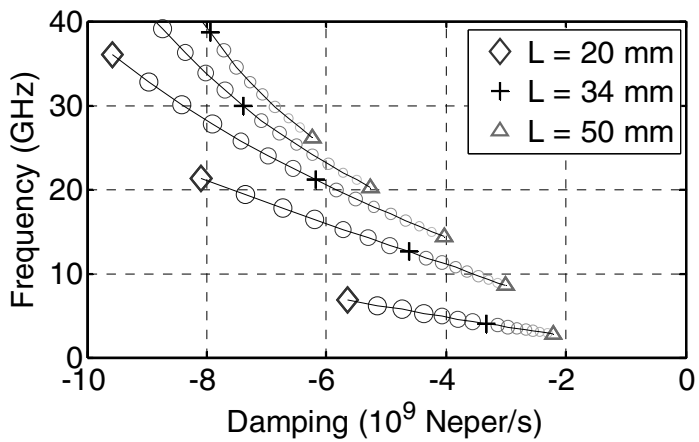

Fig. 1. Poles as a function of the dipole's length in the complex plane

For $\mathrm{L}=50 \mathrm{~mm}$, five poles are extracted between 0 and 30 $\mathrm{GHz}$, they correspond to the resonances of the dipole antenna at $\lambda / 2(3 \mathrm{GHz}), 3 \lambda / 2(9 \mathrm{GHz}) \ldots$ where $\lambda$ is the free space 
wavelength. When $\mathrm{L}$ decreases until $20 \mathrm{~mm}$, natural resonances of the dipole antenna increase to become around 2.5 times bigger. We observe that the resonant frequencies of poles increase also in a same way. Since these frequencies increase, the backscattered field decreases faster than before and the damping coefficients become much higher also in absolute value.

\section{B. Diameter variation}

We now consider the $\mathrm{L}=34 \mathrm{~mm}$ dipole antenna with a $\mathrm{L} / \mathrm{D}$ ratio varying from 30 to 700 . Poles extracted from backscattering of the dipole antenna for these L/D ratios are presented in the complex plane in Fig. 2. Poles marked with the black cross in Fig. $2(\mathrm{~L} / \mathrm{D}=700)$ are the same than those in Fig. $1(\mathrm{~L}=34 \mathrm{~mm})$.

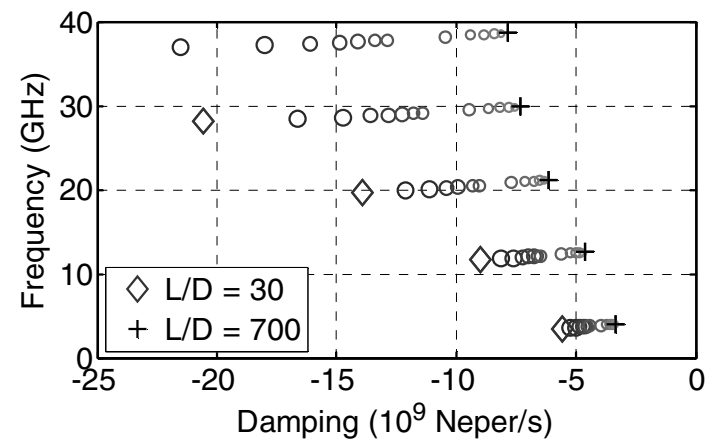

Fig. 2. Poles as a function of the dipole's diameter in the complex plane

When the $\mathrm{L} / \mathrm{D}$ ratio decreases, the resonant frequencies slightly decrease. Indeed, the physical length of the dipole increases which imply a lower resonant frequency. However, damping coefficients increase a lot in absolute value and it is linked to the lower quality coefficients of these dipoles with larger $\mathrm{L} / \mathrm{D}$ ratios.

\section{Load variation}

In this part, the sensitivity of the SEM as a function of the antenna load impedance is studied. We consider the thin dipole antenna with $\mathrm{L}=34 \mathrm{~mm}$ and $\mathrm{L} / \mathrm{D}$ ratio equal to 700 . Poles are then extracted for several load impedances from short circuit (SC) to open circuit (OC). These poles are presented in the complex plane in Fig. 3.

We can see that for load impedances from the SC to $550 \Omega$, the resonant frequencies are stable and they are located at the serial resonances of the dipole (resonances at $\lambda / 2,3 \lambda / 2 \ldots$ ). However, the damping coefficients increased a lot in absolute value because the dipole antenna becomes less resonant. For load impedances starting from $1300 \Omega$ to the OC, resonant frequencies are stable again but they are located at the parallel resonances of the dipole antenna (resonances at $\lambda, 2 \lambda \ldots$.). Since the dipole antenna becomes more resonant at these frequencies, damping coefficients decrease in absolute value.

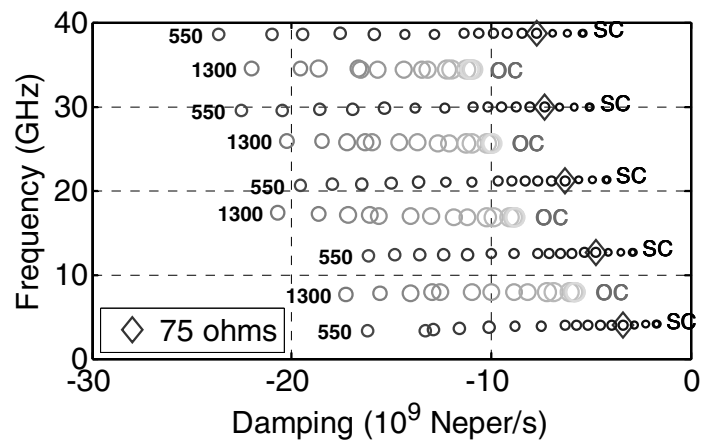

Fig. 3. Poles as a function of the dipole's impedance load in the complex plane

\section{CONCLUSION}

To the authors' knowledge, this is the first time that the SEM sensitivity has been studied in order to identify antennas. These three analyzes, regarding the length, the diameter and the load impedance of a dipole antenna, show that the SEM is very sensitive to these parameters and is able to discriminate two dipole antennas with only a slight difference on its dimensions. Moreover, the variation of the poles in the complex plane as a function of the antenna load impedance seems to be a good way to understand the change of behavior of the antenna.

\section{ACKNOWLEDGMENT}

This work has been financially support by the DGA, a part of the French ministry of defense.

\section{REFERENCES}

[1] C. E. Baum, "On the singularity expansion method for the solution of electromagnetic interaction problems," EMP Interaction Note 8, Air Force Weapons Laboratory, Kirkland AFB, New Mexico, 1971.

[2] C. E. Baum, E. J. Rothwell, K. M. Chen and D. P. Nyquist, "The singularity expansion method and its application to target identification," Proceedings of the IEEE, vol. 79, no 10, pp1481-1492, Oct. 1991.

[3] S. Licul and W. A. Davis, "Unified frequency and time-domain antenna modeling and characterization," IEEE Transactions on Antennas and Propagation, vol. 53, no 9, pp 2882-2888, 2005.

[4] C. Marchais, B. Uguen, A. Sharaiha, G. L. Ray and L. Le Coq, "Compact characterisation of ultrawideband antenna responses from frequency measurements," IET Microwaves, Antennas \& Propagation, vol. 5 , Issue: 6, pp 671-675, 2011.

[5] F. Sarrazin, J. Chauveau, P. Pouliguen, P. Potier and A. Sharaiha, "Accuracy of singularity expansion method in time and frequency domains to characterize antennas in presence of noise," IEEE Transactions on Antennas and Propagation, vol. 62, no 3, to be published.

[6] F. Sarrazin, A. Sharaiha, P. Pouliguen, P. Potier and J. Chauveau, "Comparison of antenna poles extracted from radiated and scattered fields," IEEE EUropean Conference on Antennas and Propagation, pp 797-800, 2013.

[7] T.K. Sarkar and O. Pereira, "Using the Matrix Pencil method to estimate the parameters of a sum of complex exponentials," IEEE Antennas and Propagation Magazine, vol. 37, pp 45-55, Feb. 1995. 